\title{
Os tempos das piracemas: diálogo entre Ecocrítica e Pós-Colonialismo
}

\author{
Francisco Neto Pereira Pinto ${ }^{1}$ \\ Hilda Gomes Dutra Magalhães ${ }^{2}$ \\ Universidade Federal de Tocantins
}

Resumo: Analisamos, neste artigo, a crônica A piracema do Tocantins, de Murilo Brandão Vilela, utilizando, para tanto, como referencial teórico, a Crítica Pós-Colonial e a Ecocrítica. Ao longo da análise, demonstramos no texto um descompasso entre o tempo natural da piracema e o recorte temporal da legislação ambiental a respeito, elementos que tornam ineficazes as iniciativas no sentido de proteger e preservar as condições ideais para a preservação da vida no Rio Tocantins.

Palavras-chave: Piracema. Meio Ambiente. Ecocrítica.

Analisamos, neste artigo, uma crônica de Murilo Brandão Vilela, tomando como norte a categoria tempo e, como referencial teórico, teorias dos campos da Crítica Pós-Colonial e da Ecocrítica. O artefato eleito é A piracema do Tocantins, no qual o cronista parte de um evento natural, um acontecimento real, a piracema no rio Tocantins, para questionar o recorte temporal que a legislação ambiental estabelece para o acontecimento do fenômeno no rio Tocantins, tentando mostrar que há um descompasso entre o tempo de a piracema acontecer, enquanto ocorrência no mundo natural, e o tempo estabelecido pelas autoridades legislativas para a sua ocorrência.

Para tanto, recorremos aos estudos da ecocrítica, definido por Cheryll Glotfelty e Harold Fromm como "o estudo da relação entre literatura e o meio ambiente físico" (apud SLOVIC, 1999, p. 6). Para Scott Slovic (1999, p. 6), o campo ecocrítico pode ser descrito como "o estudo de textos explicitamente ambientais por meio de qualquer abordagem acadêmica ou, inversamente, o escrutínio das implicações ecológicas e das relações homem/natureza em qualquer texto literário, mesmo que esse texto pareça, à primeira vista, não se referir ao mundo não humano". Estamos concebendo, pois, neste trabalho, a ecocrítica como a crítica acadêmica de orientação ambientalista, que, como diz Adele Bealer (2012), a partir de uma dinâmica diversidade metodológica e crítica, focaliza aspectos ambientais em

\footnotetext{
${ }^{1}$ Doutorando em Ensino de Língua e Literatura pela Universidade Federal do Tocantins, campus de Araguaína e professor no Instituto Presidente Antônio Carlos - ITPAC, Araguaína, Tocantins. E-mail: fneto@uft.edu.br.

${ }^{2}$ Doutora em Teoria da Literatura pela UFRJ, com pós-doutorado na Universidade de Paris III e EHESS/França. Prof ${ }^{\text {a }}$. aposentada pela UFT/Tocantins. E-mail: hildadutra61@gmail.com.
} 
produções de caráter artístico ou não.

No que se refere à crítica pós-colonial, é bom consignar que não se trata de uma única vertente teórica, posto que os termos teoria pós-colonial, pós-colonialismo ou mesmo estudos pós-coloniais carregam consigo cargas semânticas que sinalizam para as mais variadas direções ideológicas, políticas e mesmo institucionais. O(s) adjetivo(s) "pós-colonial(is)" e o substantivo "pós-colonialismo" têm servido de mote a investigações de vários teóricos e alimentado disputas entre muitos deles. Note-se, por exemplo, o estudo de Ella Sohat (1992), que visa, dentre outros objetivos, interrogar o termo pós-colonial, não para meramente anatomizá-lo semanticamente, como ela mesma diz, mas "para situá-lo geográfica, histórica e institucionalmente" (SOHAT, 1992, p.100), levantando questões "sobre seu desenvolvimento a-histórico e universalizante e suas potencialmente implicações despolicizantes" (SOHAT, 1992, p. 99). A autora considera o termo ambíguo tanto do ponto de vista político quanto do teórico, bem como portador de vários erros conceituais. Outro exemplo é o de Ania Loomba (1998) que, em seu artigo "Postcolonlism - or postocolonial studies", manifesta desconforto “com o modo como as palavras pós-colonial e pós-colonialismo foram usadas, de modo a se semelharem a estudos pós-coloniais ou teoria pós-colonial" (LOOMBA, 1998, p. 39) por Robert Young (1998), no artigo "Ideologies of the postcolonial".

De fato, ao oferecer uma definição ao termo pós-colonialismo, Young (1998) não parece estar mesmo preocupado com essas distinções. No entanto, Loomba (1998), em seu trabalho, se dedica, por quatro páginas, a mostrar que os reducionismos de Young são presunçosos e problemáticos e, para isso, apresenta várias razões que, por fugir aos nossos objetivos aqui, não alistaremos. Outras questões que têm merecido atenção dos estudiosos são os afixos envolvidos nos termos em questão. Quer o prefixo "pós", quer os sufixos "ismo(s)" já foram objetos de discussão e, nesse sentido, veja-se o trabalho de Vijay Mishra e Bob Hodge (2005), no qual fazem um levantamento tanto das origens quanto das implicações semânticas dos elementos que compõem a palavra "pós-colonialismo".

Digno de nota é, também, o artigo "Is the post - in postmodernism the post - in postcolonial?”, de Kwame Anthony Appiah (1991), no qual são discutidos os significados que envolvem tanto a condição pós-moderna quanto a de pós-colonialidade e, por fím, se o "pós", em pós-moderno, é o mesmo que em pós-colonial, e o resultado é que, a depender do sentido em que é empregado, outro é o significado que reveste o prefixo. Não obstante, resta claro que, em alguma medida, quer em associação ao moderno, quer ao colonial, o "pós" guardará sentido regular, qual seja, de contestação das narrativas anteriores de dominação. 
Contudo, se dermos por superadas essas questões, na medida em que elas não se mostram de maior relevância à nossa discussão, poderemos avançar a uma maior compreensão do que vem a ser a perspectiva crítica pós-colonial. Boaventura de Sousa Santos (2004, p. 8) se refere ao pós-colonialismo como

[...] um conjunto de correntes teóricas e analíticas, com forte implantação nos estudos culturais, mas hoje presentes em todas as ciências sociais que têm em comum darem primazia teórica e política às relações desiguais entre Norte e Sul na explicação ou na compreensão do mundo contemporâneo.

Este conceito pode ficar mais claro se pensarmos essas relações desiguais como se desenvolvendo no bojo da modernidade e que têm como tônica o colonialismo que aí se desenvolve tanto no âmbito político quanto no social.

Do exposto, resta claro que a orientação crítica pós-colonial se desdobra em várias perspectivas e que, portanto, é possível se encontrar várias definições para o campo de estudos, uma vez que as teorias e análises pós-coloniais se fazem presentes nos campos das ciências sociais, humanas e outros e, neste sentido, esclarece Sérgio Costa (2006, p. 117) "os estudos pós-coloniais não constituem propriamente uma matriz única”. Antes, continua o autor, "trata-se de uma variedade de contribuições com orientações distintas, mas que apresentam como característica comum o esforço de esboçar, pelo método da desconstrução dos essencialismos, uma referência epistemológica crítica às concepções dominantes de modernidade" (COSTA, 2006, p. 117); e Young (1998), por seu turno, já havia definido o póscolonialismo como um fórum transnacional para discussões acerca de problemas contemporâneos sobre globalização, cuja demanda exige trabalhos interdisciplinares. Assim se posiciona o autor:

[...] o pós-colonialismo veio nomear certo tipo de trabalho acadêmico interdisciplinar político, teórico e histórico que se presta a servir como um fórum transnacional para estudos cujos pés estejam fincados no contexto histórico do colonialismo, bem como no contexto político dos problemas contemporâneos da globalização (YOUNG, 1998, p. 4).

Veja-se que, da definição acima, pode-se inferir que estudos que se norteiam pela perspectiva pós-colonial tanto podem se voltar ao período que marca o fím do colonialismo do século XX, e aí fica restrito a esta esfera espaço-temporal, como mostra Igor José de Renó Machado (2004), como podem se referir ao colonialismo político social, que ainda hoje vige. Essas acepções acima delineadas se prestam bem a fins analíticos e, a depender do autor, podem assumir outras multiplicidades, como, por exemplo, em Arif Dirlik (1997) ao diferenciar três usos do termo que lhe parecem bem proeminentes. O primeiro tem a ver com 
uma descrição literal de condições em sociedades ex-colônias e, aí, o referencial é concreto, como as sociedades e intelectuais pós-coloniais; ao passo que o segundo é mais abstrato e descreve uma condição global após um período de colonialismo; e, o último, como "descrição de um discurso sobre as condições acima mencionadas, inspirado pelas orientações epistemológicas e psíquicas que são produtos dessas condições” (DIRLIK, 1997, p. 49).

Sousa Santos (2003), ao seu modo, distingue apenas duas acepções principais do termo. A primeira diz respeito ao período histórico pós-independência das colônias na África e na Ásia e, a segunda, como um conjunto de práticas discursivas que, ao desconstruírem a narrativa colonial escrita pelo colonizador, procuram substituí-la por aquelas escritas pelos colonizados. Esta segunda, nas palavras do autor "insere-se nos estudos culturais, linguísticos e literários e usa privilegiadamente a exegese textual e as práticas performativas para analisar os sistemas de representação e os processos identitários" (SANTOS, 2003, p. 26). De um modo geral, os estudos pós-coloniais, vistos enquanto possibilidade teórica, surgem no final da década de 1970, com Orientalism, trabalho de Edward Said, crítico literário palestino que, embora não tenha usado tal nomenclatura, tem este seu trabalho como marco inicial do que Sohat chama de projeto intelectual transnacional (SANTOS e SCHOR, 2013) e, desta visão compartilham, inclusive, Bhabha e Spivak (VIEIRA,1999, p. 274).

Esse período de nascimento dos estudos pós-coloniais é marcado pela entrada de intelectuais do terceiro mundo nas academias do primeiro mundo, notadamente europeias e norte-americanas, e, por isso, o termo pós-colonial passou a ser usado em conexão tanto com as questões já acima descritas quanto "para descrever intelectuais acadêmicos de origem terceiro-mundista" (DIRLIK, 1997, p. 8). A tríade Edward Said, Homi Bhabha e Gayatri Spivak tem sido considerada a mais expressiva dentre os teóricos pós-coloniais (CASTROGÓMEZ, MENDIETA, 1998), porém, sem entrar no mérito da questão, pode-se a ela acrescentar outros importantes nomes como, por exemplo, Ranajit Guha, Partha Chatterjee, Dipesh Chakrabarty, Gyan Prakash e Kwame Appiah e hoje, mais ainda, outros.

A crítica pós-colonial surge, então, como uma abordagem alternativa à compreensão do imperialismo, das colonizações e das colonialidades e suas influências tanto como fenômeno mundial quanto localizado; envolve, assim, constantes questionamentos no que toca a essas e outras relações igualmente importantes para compreensão tanto da cultura quanto da política na era da descolonização. A preocupação do crítico deve girar, então, "em torno da criação de um contexto favorável aos marginalizados e oprimidos, para a recuperação da sua história, da sua voz, e para a abertura das discussões acadêmicas para 
todos" (BONNICI, 2000, p. 10). Se o pós-colonial pode ser descrito tanto como um paradigma histórico como epistêmico em formação (HALL, 2006), a partir deste último, a perspectiva pós-colonial emerge não somente do testemunho colonial dos países do terceiro mundo, mas também dos discursos das minorias "dentro das divisões geopolíticas de Leste e Oeste, Norte e Sul" (BHABHA, 2005, p. 239).

Nesse sentido, é muito importante pensar o fenômeno globalização e seus efeitos em torno do eixo colonização, o que nos propomos a pensar, neste trabalho, em conexão com a modernidade. Se, por um lado, como diz Charles Baudelaire (1996, p. 26) a modernidade "é o transitório, o efêmero, o contingente", por outro, de acordo com Marshall Berman (1986, p. 15), ela "une a espécie humana"; paradoxalmente, pois os discursos ideológicos da modernidade tentam "dar uma 'normalidade' hegemônica ao desenvolvimento irregular às histórias diferenciadas de nações, raças, comunidades, povos" (BHABHA, 2005, p. 239 ênfase no original) e, neste respeito, a crítica pós-colonial intervém.

A crítica pós-colonial, em suma, "é testemunha das forças desiguais e irregulares de representação cultural envolvidas na competição pela autoridade política e social dentro da ordem do mundo moderno" (BHABHA, 2005, p. 239) e, ao passo que formula revisões críticas em torno das questões acima levantadas, "permite a autenticação de histórias de exploração e o desenvolvimento de resistências" (BHABHA, 2005, p. 26) daqueles que, de uma forma ou de outra, não se encaixam nos discursos e práticas hegemônicos da modernidade. O pós, assim, em pós-colonial, pode expressar, do ponto de vista epistêmico, não uma superação dos efeitos dos domínios coloniais em suas distintas configurações, nem mesmo a cessação das relações desiguais e conflituosas no jogo poder/saber entre povos, comunidades etc., mas, antes, pode apontar para um tempo revisionário e de reinscrição, ou seja, "um retorno ao presente para redescrever nossa contemporaneidade cultural; reinscrever nossa comunalidade humana, histórica; tocar o futuro em seu lado de cá" (BHABHA, 2005, p. 27 - ênfase no original).

Tocar o futuro em seu lado de cá, como um de seus aspectos, tem a ver com uma revisão da noção de tempo eurocêntrico, ou tempo da modernidade; tempo linear, vazio, homogêneo e fluído; tempo do progresso e da globalização, tempo que procura emprestar invisibilidade e, portanto, que retira as forças de significação de todas as demais temporalidades que não se conformam aos limites traçados pelo projeto da modernidade. Especificamente sobre a reinscrição de outras temporalidades que, neste artigo, a perspectiva pós-colonial interessa à Ecocrítica e é desse assunto que nos ocuparemos de agora em diante. 
A Ecocrítica, tida, do ponto de vista da teoria literária, enquanto crítica acadêmica de orientação ambientalista, nos fornece base para empreendermos leitura dos textos literários em uma direção ecológica, de modo a explorar neles visões tanto de natureza quanto da relação entre homem e meio ambiente físico natural. Se, por um lado, a Ecocrítica não nos permite discutir problemas de ecologia, por outro, nos confere suporte, de modo a ler nos textos afirmações sobre problemas ecológicos, ou seja, sobre como aí o meio ambiente físico natural, o próprio homem e as relações que entre eles se estabelecem são percebidos e, para além disso, como gostaríamos que fossem.

No entanto, se, como diz Garrard (2006), a Ecocrítica se confronta com a necessidade de pensar sua relação com a globalização de modo a estar atenta aos problemas materialmente postos nas questões globais na atualidade, com o fim de postular uma poética da responsabilidade para com o lar terrestre, também é patente a necessidade de chamar à cena a experiência construída por outros métodos de leitura que se ocupam de questões relacionadas com a globalização, e, como a Ecocrítica é, confessadamente, uma abordagem interdisciplinar, é nesse cenário que a Crítica Pós-Colonial intervém, pois, como diz Anthony Giddens (1991, p.69), “a modernidade é inerentemente globalizante”. Um dos aspectos implicados na questão da modernidade, que se estende ao mundo inteiro com o processo de globalização, é a noção de tempo eurocêntrico, que reúne como características, por exemplo, a unidirecionalidade, o vazio, a linearidade e universidade.

Não é de somenos importância à Ecocrítica o enfrentamento de questões relativas ao tempo, pois, como diz David Harvey (2006, p. 188), “o horizonte temporal implicado numa decisão afeta materialmente o tipo de decisão que tomamos”. Se, como diz Giddens (1991), um dos pilares da modernidade é a conquista de uma concepção unitária de tempo apropriada ao industrialismo, à burguesia e à dominação de impérios europeus sobre o resto do mundo, e, se é na modernidade que a natureza passa a ser colonizada pelo homem, então esse é um dos assuntos em que o diálogo entre Ecocrítica e Crítica Pós-Colonial pode se mostrar produtivo (ANTHONY, 2008). Mais especificamente, a Crítica Pós-Colonial coloca questionamentos ao tempo pedagógico (BHABHA, 2005), desnaturalizando-o e o revelando como estando em conexão com uma história de dominação da Europa sobre o resto do mundo e, também, do homem sobre a natureza. Igualmente, uma vez desconstruída a noção de tempo pedagógico, a Crítica Pós-Colonial propõe o que Bhabha (2005) chama de temporalidade performática, revelando, assim, possibilidade de se propor engajamentos a favor de temporalidades apropriadas ao paradigma ecológico. 
A sociedade do Estado-Nação tem como principio, como se sabe, a unidade. Um povo, um espaço, uma língua, uma história e, como não poderia deixar de ser, um tempo. É como diz Homi Bhabha, “de muitos, um" (2005, p. 203 - ênfase no original). A esse tempo uno, que une muitos povos em um só e os inscreve na ordem da História, Bhabha (2005, p. 207) chama de tempo pedagógico, que diz respeito "a temporalidade continuísta, cumulativa", quer dizer, tempo homogêneo, o da modernidade. O tempo pedagógico, do qual fala Bhabha (2005, p. 209), é descrito como "encapsulado numa sucessão de momentos históricos que representa uma eternidade produzida por autogeração" e, dito assim, não fica difícil se perceber que se trata de uma noção discursiva de tempo que corresponde a uma das grandes narrativas do século XIX que, aliada ao historicismo, dá sustentação ao "passado" do "povo" e funda a possibilidade de sua genealogia e o estabelecimento de identidade cuja autoridade se pauta na tradição e se perde no imemorável.

Como não corresponde a um referente externo, esse tempo se reproduz por autogeração, ou seja, funda sua identidade partindo de si mesmo - com prejuízos às demais temporalidades - e sedimenta-se, por curso, erguendo-se em monumentalidade, e é nesse sentido que entendemos a afirmação de Bhabha (2005, p. 216), quando diz que o tempo pedagógico corresponde à "circulação simultânea do tempo linear, cursivo, monumental". Essa noção de tempo é pedagógica também porque a sincronia coloca o passado sempre, em relação ao presente, como lição: "como no passado". No contexto da modernidade, isso nos leva à "pedagogia dos símbolos do progresso" (BHABHA, 2005, p.338 - ênfase no original).

Se, na Idade Média, predominava a providência divina, na Idade Moderna predominará o que Giddens (1991, p. 54) chama de providência da razão e do progresso, e a essa ideia de razão "coincidiu a ascensão do domínio europeu sobre o resto do mundo" (GIDDENS, 1991, p. 54). A modernidade, assim, presenciaria não somente o domínio do Europeu sobre o resto do mundo, mas, também, principalmente a partir da filosofia de René Descartes, o domínio do homem sobre a natureza. Descartes, conforme declara Garrard (2006, p. 44), "hiperseparou a mente e o corpo e negou aos animais não apenas a faculdade da razão, mas toda a gama de sentimentos que havia associado ao pensamento". Uma das consequências desse modo binário de pensamento, que separa homem/natureza, mente/corpo, razão/emoção, é que o homem passa a ser visto como radicalmente diferente da natureza e superior a ela. Contudo, nem sempre foi assim, pois, antes do advento da modernidade, na maior parte das culturas, "mesmo nas grandes civilizações, os seres humanos se viam em continuidade com a natureza" (GIDDENS, 1991, p. 66). Porém, a racionalidade científica e a 
crença no progresso, dispõem a natureza às necessidades do homem e este agora arroga a si o direito de "transformá-la em recurso e explorá-la o máximo possível, a bem da civilização e do desenvolvimento" (FREITAS, 2008, p. 17).

Por fim, vale ressaltar, retomando ainda a questão do tempo, que, embora as ideias de tempo cíclico, que colocava o homem em continuidade da natureza, e a de tempo linear coexistissem já na Idade Média, é em meados do século XVII que "o homem finalmente contou com um marcador de horas exato, mostrando a passagem contínua de anos a fio. Isso influenciou muito o conceito moderno de homogeneidade e continuidade do tempo" (WHITROW, 2005, p.29). Não é de surpreender que seja essa a concepção de tempo ainda prevalecente no Ocidente, pois, mesmo na Idade Média, "a concepção linear era promovida pela classe mercantil e pela ascensão de uma economia monetária” (WHITROW, 2005, p. 25), uma vez percebiam que tempo é dinheiro e, portanto, deviam usá-lo de forma econômica. Temos, assim, por traçada a relação entre tempo pedagógico e modernidade. Não somente isso, mas a relação entre essa noção de tempo e a devastação do ambiente físico natural pelo homem.

Porém, a crítica pós-colonial não somente identifica o tempo pedagógico como também propõe uma revisão em torno dessa noção de temporalidade. Neste caso, colocamonos a falar do que Bhabha (2005) chama de tempo performativo, o que se relaciona com o "tocar o futuro do lado de cá”, conforme já destacado e, eis, então, uma contribuição da crítica pós-colonial à Ecocrítica. Dirlik (1997, p. 28) diz que "a metanarrativa do progresso que fundamentou dois séculos de pensamento está em profunda crise" e, assim, a ideia de que a humanidade sempre avança de um estágio inferior em direção a uma condição melhor em um caminhar de aperfeiçoamento não foi capaz de se sustentar diante dos muitos horrores do século XX. Não há como negar os impactos das grandes Guerras Mundiais e das muitas menores que as seguiram, do Holocausto e do terrorismo em suas muitas formas, só para citar, na ideologia do progresso.

No entanto, não só ao progresso, pois, como já ressaltamos, correlata a este há a ideia de um tempo linear, unidirecional e universal que progride ao infinito. A crise da ideologia do progresso acarreta, por conseguinte, a do tempo que lhe é solidária e, nesta direção, Dirlik (1997, p. 28) diz que "o mundo tornou-se tão confuso em relação ao espaço quanto a ideologia do progresso em relação ao tempo". Pode-se dizer, em adição, que o século XX presenciou não somente o desgaste das noções de progresso e do tempo eurocêntrico, mas também a emergência de outras temporalidades e, com elas, a possibilidade de escrita e 
inscrição de outras histórias que, até então, eram impossíveis ou invisibilizadas pelas metanarrativas ocidentais. Como já enfatizado, a crítica pós-colonial, de fato, engaja-se pela legitimação e emancipação dessas histórias marginais, que são excêntricas ao já instituído e legitimado pelo poder de exercício das metanarrativas.

É bom que se ressalte, entretanto, que isso não se dá sem esforço, de modo tranquilo. Afinal, trata-se de luta pelo direito de significar, logo, embates por sentidos outros que não os já cristalizados. É nesta direção que lemos as palavras de Bhabha (2005, p. 240), quando diz: "isto demanda uma revisão radical da temporalidade social na qual histórias emergentes possam ser escritas". Não há, logo se percebe, como histórias marginalizadas significarem com pleno direito se tomado como parâmetro o tempo pedagógico, do Estado-Nação. Como já ressaltado, o tempo pedagógico ergue-se como monumento e embasa a dicotomia desenvolvido/subdesenvolvido ou moderno/atrasado. Desse modo, tudo que não se conforma aos padrões "modernos" é, portanto, atrasado e não lhe resta mais nada, pela ótica do progresso, senão estabelecer como alvo percorrer os trilhos do "desenvolvimento". Não é sem razão, pois, que Bhabha proponha uma revisão radical da temporalidade social pedagógica.

Pensando a temporalidade do Estado-Nação, Bhabha (2005) fala também de outros tempos que são subsumidos em nome do tempo pedagógico. Se, por um lado, a temporalidade pedagógica dilui os "muitos" em "um" e, por esforço da repetitividade ou da performance, ensaia sua própria autogeração, por outro lado, no movimento performático, paradoxalmente, a cada retorno se revela retalhado por temporalidades por vezes antagônicas, dissidentes e incomensuráveis. Essas outras temporalidades somadas à temporalidade pedagógica constituem uma arena de luta, logo um espaço contencioso, em que o presente da modernidade é deslocado e se torna disjuntivo, negando, dessa maneira, a plausibilidade de um presente homogêneo, universal, que comporta todo o passado e projeta um futuro. Essa temporalidade disjuntiva, que constitui o tempo performático, é da maior importância, pois, como diz Bhabha (2005, p. 247), "ela cria um tempo de significação para a inscrição da incomensurabilidade cultural".

Interessa-nos pensar o discurso ecocrítico em conexão com a temporalidade performática, posto que Bhabha fala, na última citação, da possibilidade de se criar um tempo de significação àquilo que é incomensurável e, neste ponto, acrescentaríamos, então, ao discurso ecológico. Entendemos ser necessário pensarmos uma temporalidade que seja adequada aos valores, à mentalidade, às práticas, à ética, ao paradigma ambiental, de modo a se postular um modo de viver que seja condizente com a sustentabilidade da vida e do direito 


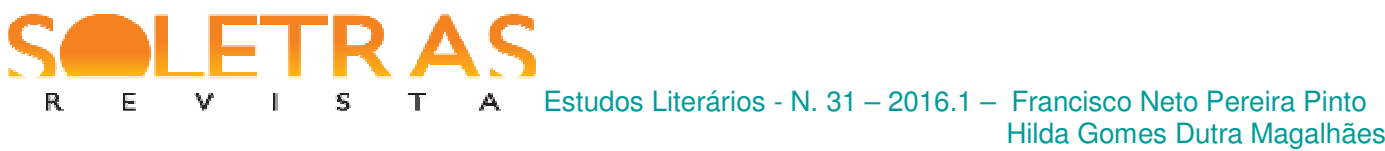

de todos os habitantes da biosfera viverem, não somente na perspectiva do hoje, mas também das gerações futuras. Tomando como base os postulados já enunciados, é que empreendemos a leitura de uma crônica de Murilo Brandão Vilela. ${ }^{3}$

\section{O tempo do estado e os tempos das piracemas}

O conceito de nação nasce em conexão com o Iluminismo e a Reforma, numa época em que esses "estavam destruindo a legitimidade do reino dinástico hierárquico, divinamente instituído" (ANDERSON, 1989, p. 15); ela nasce com um desejo, o de "ser livre e soberana" (FESTINO, 2007, p. 38) e, neste novo arranjo, "o penhor e o símbolo dessa liberdade é o Estado soberano" (ANDERSON, 1989, p. 15). Se nos reinos dinásticos hierárquicos os reis reinavam por designação divina, o símbolo máximo no Estado-Nação é o próprio Estado, e, embora toda nação seja, na realidade, heterogeneamente constituída, ela é imaginada como "comunidade, porque sem considerar as desigualdades e exploração que atualmente prevalecem em todas elas, a nação é sempre concebida como um companheirismo profundo e horizontal" (ANDERSON, 1989, p. 16 - ênfase no original).

Ainda, para este mesmo autor, um dos elementos que conferem coesão e unidade a essa comunidade, a nação, é o tempo, concebido enquanto homogêneo, vazio e unidirecional, que sustenta uma escrita histórica que lança as raízes do povo da nação em um passado imemorial e, assim, os muitos se tornam um, no dizer de Bhabha (2005). O tempo da nação é o tempo do calendário e do relógio mecânico, que já o chamamos, com base em Bhabha (2005), de tempo pedagógico. Este tempo, que na verdade é discursivizado, pelo modo como é estruturado se apresenta em roupagem de natural, autônomo, que tem seu curso alheio às ações do homem e, portanto, se coloca como indiferente a ele. Porém, se, conforme vimos com base em Giddens (1991), nas sociedades pré-modernas o tempo colocava o homem em coextensividade com a natureza, na figura do Estado-Nação o tempo é o do calendário cristão, e o Estado, ao mesmo tempo em que a ele está sujeito, pode nele intervir. Mais que isso, agora o tempo não só independe dos movimentos regulares naturais, como também se sobrepõe às temporalidades inerentes à natureza.

Nesse sentido, vejamos as palavras de Elias (1998), quando diz:

3 Murilo Brandão Bahia Vilela nasceu em Viçosa, Alagoas, em $1^{\circ}$ de janeiro de 1935. Passou sua infância no Engenho Mata Verde, a $10 \mathrm{~km}$ de Viçosa e, após fazer a faculdade de Medicina, veio, aos 25 anos, morar no Tocantins. Residiu por cerca de 50 anos na cidade de Tocantinópolis, TO, onde exerceu a Medicina e morreu no dia 19 de maio de 2011. 
[...] uma expressão do tipo 'quando sentimos frio' é característica do modo de determinação do tempo nas sociedades em estágio primitivo de desenvolvimento. Num estágio um pouco mais avançado, um grupo humano talvez já disponha do símbolo mais impessoal 'inverno'. Hoje em dia, servimo-nos no mundo inteiro de um calendário que indica em que mês começa o inverno; e esse calendário é utilizado também pelos homens que vivem em regiões do globo onde, durante os 'meses de inverno', a temperatura continua muito amena (ELIAS, 1998, p. 29-30 - ênfase no original).

As palavras do autor deixam claro como o tempo pedagógico se universalizou e sua influência se expandiu de modo a atingir até mesmo os fenômenos naturais na medida em que os homens com eles estabelecem relação. Muito embora o calendário não possa produzir o inverno, enquanto fenômeno natural, ele pode, e de fato estabelece, o período de inverno enquanto estação do ano, que é observado pelos homens nas relações que estabelecem uns com os outros com base nesse marco temporal. Essas considerações nos conduzem à crônica "A piracema”, o texto de Vilela (2006), escolhido para análise. Um trecho selecionado diz: "Como é que, num país imenso como o nosso, pode haver uma única lei ambiental capaz de determinar as enchentes, a qualidade da água e, consequentemente, a formação das piracemas?" (VILELA, 2007, p. 29).

Do extrato é possível observar o confronto que o cronista coloca em perspectiva entre duas temporalidades: uma, a da formação da piracema, enquanto evento natural, e uma outra, que também se refere à formação de piracema, mas no plano da legislação ambiental. $\mathrm{O}$ confronto se evidencia pelo descompasso que há entre a ordem de determinação de uma sobre a outra, ou seja, há uma sobredeterminação da norma legal sobre o evento natural, regulando seu acontecimento. Observe-se que não é o evento natural, enquanto acontecimento em toda a sua complexidade, que inspira o fazer normativo, mas, ao contrário, é a norma que determina tanto a "as enchentes, a qualidade da água e, consequentemente, a formação das piracemas".

Dito de outro modo, temos o poder normativo do Estado a intervir, virtualmente, nas temporalidades das formações das piracemas, de modo a aplainá-las e conformá-las ao tempo do calendário. Destaque-se que o cronista fala mesmo de "determinar", ou seja, a norma não acolhe as ordens temporais das diversas piracemas que se instauram de fato, mas determina um período temporal para que as piracemas ocorram, como se essa determinação pudesse produzir as ocorrências desses eventos naturais. Não há, mais, uma figura divina a reger o tempo, há, antes, a figura do Estado como símbolo máximo. Perceba-se, mais ainda, o desdém do cronista em relação à universalização do tempo para ocorrência das condições climáticas favoráveis à formação da piracema em todo o país. Embora não seja, para além do mundo 
ficcional criado pelo autor, possível encontrar no sistema legal brasileiro uma única portaria que delimite o marco temporal para início e fim do evento piracema em todo o país, no geral, as várias portarias que se ocupam do assunto elegem "entre novembro e fevereiro, como período nacional, imutável, para a migração reprodutiva dos peixes reofílicos" (VILELA, 2007, p. 29), ou seja, dos peixes que migram para reprodução.

Para se constatar isso, basta ler as instruções normativas $n^{\text {os. }} 36,39,40,49$ todas do ano de $2005^{4}$ e emanadas do IBAMA - Instituto Brasileiro do Meio Ambiente e dos Recursos Naturais Renováveis. Nos documentos legais, verificam-se pequenas variações no que diz respeito aos períodos estabelecidos, o que, todavia, não implica, necessariamente, heterogeneidade e que as piracemas em todo o país sejam levadas em consideração individualmente. Em sua grande maioria, os períodos estabelecidos para as piracemas nas várias bacias hidrográficas brasileiras, pelas instruções mencionadas, coincidem com o período que vai de $1^{\circ}$ de novembro a 28 de fevereiro do ano seguinte. A essa sobreposição do tempo da norma aos acontecimentos do mundo natural, o cronista classifica de absurdo e, em suas palavras: "há, de princípio, um absurdo que não passa despercebido aos mais humildes observadores" (VILELA, 2007, p. 29). A razão? Para o cronista, a piracema é evento complexo que não se deixa prender à fixidez ao tempo absoluto ao qual a norma se filia, dado que o tempo da piracema é instável, tempo da conjunção subordinativa causal se.

"Haverá, sempre, um se, diante dos fenômenos naturais que o transforma em denominador comum dos acontecimentos climáticos e ambientais" (VILELA, 2007, p. 30). Pela ótica do cronista, se, e apenas se, as condições ambientais forem propícias, haverá piracema, e essa proposição parece acertada, pois, como diz Nicolle Albornoz Pesoa (2004), as estratégias reprodutivas dos peixes reofílicos, ou seja, daqueles que migram para fins de reprodução - fazendo, então, piracema - levam em conta fatores biológicos e ambientais e, dentre os fatores determinantes para o acontecimento piracema, está o nível hidrológico, ou seja, é necessário que haja fluxo de água volumoso. No entanto, não basta que hajam cheias. Há que se levar em consideração uma série de variante, pois, como afirma Pesoa (2004, p. 11), as "variações na duração, época e magnitude das cheias afetam as espécies de maneira diferenciada, visto que as exigências ecológicas e a cronologia dos processos vitais, como reprodução, alimentação, maturidade e crescimento, são distintas entre as espécies".

Assim sendo, não é de surpreender que o cronista coloque em suspensão a fixidez do período estabelecido pela norma para a realização da piracema no rio Tocantins e afirme que

\footnotetext{
${ }^{4}$ A legislação de 2005 foi escolhida para consulta porque este foi o ano em que foi escrita a crônica em análise. SOLETRAS - Revista do Departamento de Letras da FFP/UERJ Número 31 (jan.-jun. 2016) ISSN: 2316-8838

DOI: 10.12957/Soletras.2016.22110
} 
aí, nesse rio, o evento natural só ocorra se as condições forem propícias a isso. É nesta mesma direção que aponta Francisco Manoel de Souza Braga (1990) que, em pesquisa realizada no rio Tocantins, constata haver, a depender da espécie, distintos períodos de reprodução, tanto em períodos de cheia, quanto de pré-cheia, o que inclui espécies reofílicas, como a curimata amazônica. O fato é que, como diz Braga (1990, p. 557), "a relação existente entre as espécies de peixes e as condições ambientais resultantes de um período seco e outro de cheia do rio Tocantins é intensa, e oferece a elas as oportunidades adequadas para o desenvolvimento de todo o processo reprodutivo e alimentar".

Contrapondo a realidade da piracema no rio Tocantins com o que ocorre no Pantanal, o texto de Vilela diz:

\begin{abstract}
Ainda ontem, a televisão mostrava o Pantanal em sua enchente máxima, prenunciando fartura de piracemas. A informação está absolutamente certa, uma vez que o Pantanal é uma imensa planície com inúmeros rios e lagos que se unificam num mar de água doce, invadindo campinas e matas, oferecendo aos peixes a suprema abundância da alimentação. Como não há correnteza nas planuras alagadas, as águas sujas, que formam as enchentes, em poucos dias estarão limpas pelo fenômeno físico da decantação. Com sol e sombra, água fresca e alimentação farta, está constituído o paraíso da ictiofauna. Os peixes, bem nutridos, despertam para a reprodução. Vão se juntando, aos grupos, e em pouco tempo serão milhares os alegres participantes das piracemas. No Pantanal é assim, no Tocantins, não (VILELA, 2006, p. 30).
\end{abstract}

Há algo a observar no modo como o cronista se refere ao evento piracema. Mesmo no Pantanal, na linguagem do texto, fazem-se piracemas, no plural. Comparando com o que acontece no Tocantins, o narrador coloca em perspectiva que, embora sejam eventos da mesma natureza, eles acontecem em circunstâncias diferentes, e isso não é levado em conta pela legislação ambiental. Assim, o que é válido para uma região, pode não o ser para outra e, igualmente, as diferentes espécies guardam suas particularidades. Inadequado, pois, é o tempo pedagógico do Estado, na regência dos eventos piracemas. As temporalidades das piracemas, são, assim, outras. E não se trata, também, de se falar em um tempo das piracemas, mas em tempos das piracemas, dado que, como vimos, o cronista ressalta tanto as diferenças e particularidades do evento lá, no Pantanal, e aqui, no rio Tocantins. Ademais, como já evidenciado, espécies diferentes, por vezes, fazem piracemas em épocas diferentes.

Evidentemente, não é sem consequências graves que se dá a sobredeterminação do tempo institucional, determinado pelo Estado, sobre os tempos das piracemas enquanto eventos naturais, uma vez que, em não havendo condições propícias: "fazem-se piracemas de novembro a fevereiro e, consequentemente, fazem-se fiscalizações, rudes, inócuas, injustas e 
desonestas, numa piracema que não existe no Tocantins" (VILELA, 2007, p. 30). Podemos sublinhar daí que a questão do tempo não é, jamais, de somenos importância, se levarmos em consideração que a noção de temporalidade que informa nosso percurso no mundo faz sentir seus efeitos em nossas ações concretas, e um exemplo disso é o que colocou o cronista no último extrato mencionado.

A temporalidade do Estado coloca seu aparato de vigilância a realizar fiscalização em um período de piracema que não existe, mas que pode acontecer a qualquer momento, porém, segundo uma escala temporal alheia ao calendário cristão, logo, ao tempo do Estado. Deste modo, perde o Estado, com todos seus gastos e esforços dispendidos inadequadamente, e perde também a natureza, que não tem seus processos e particularidades respeitados. Perde, enfim, com essa visão cegante, todos nós, habitantes da biosfera, que somos adversamente afetados pela inocuidade da temporalidade pedagógica, que desrespeita os ciclos vitais.

\section{Tempo de cuidar}

Se os tempos por que passamos é de crise ecológica e isso desperta posições ora de negação do fato, ora de profecias apocalípticas, ou, ainda, do politicamente correto, o texto de Vilela indica nova direção. Ele aponta para uma relação de responsabilidade do homem para com o meio em que está inserido, seu meio ambiente, e isso, certamente, requer a desconstrução do paradigma vigente pautado no individualismo e no uso do ambiente físico natural de modo abusivo e irresponsável, conforme podemos visualizar no trecho abaixo:

É bom que se pense, mais uma vez, numa eficiente arma de defesa dos nossos peixes, como as imensas e bondosas mãos dos que protegem os mais fracos e apontam os caminhos da conscientização cultural, da vigilância efetiva e da proibição radical de qualquer tipo de rede (VILELA, 2006, p. $31)$.

Com a desnaturalização desse paradigma, um outro poderá ganhar visibilidade, este com bases em um outro modo de o homem se relacionar com o mundo natural. Neste, o homem não é mais as mãos que destroem como a um inimigo que precisa ser vencido, ou como algo infinito que jamais esgotará, ou como bens a serviço do capital e do consumo desenfreado e insustentável, mas, como diz Vilela, "como as imensas e bondosas mãos dos que protegem os mais fracos" (VILELA, 2005, p. 31). Esse novo paradigma, o da responsabilidade, passa pelos “caminhos da conscientização cultural” (VILELA, 2005, p. 31), pelos quais novos sentidos podem ser atribuídos tanto ao homem, ao meio em que vive e à 
relação homem/natureza, e, apropriadamente, podemos afirmar que os escritos de Vilela se relacionam intimamente com a consciência ecológica. Nessa direção, Maria João Reynaud diz:

A preocupação ecológica actual nasce da necessidade de mitigar o esgotamento dos recursos naturais, como condição de sobrevivência a médio prazo, o que exige não apenas um esforço de solidariedade, traduzido em acções concretas, mas um novo modo de relação do ser humano com a natureza que poderá significar o regresso do filho pródigo à tellus mater (2009, p. 4).

Ademais, a proposta do cronista de conscientização cultural, aliada a uma vigilância efetiva e da proibição radical de qualquer tipo de rede, o que seria uma poderosa arma de defesa dos peixes, se aplicada, por extensão, à questão ecológica de um modo geral, enseja um olhar orientado "para os problemas práticos da responsabilidade" (GARRARD, 2006, p. 241), podendo, assim, viabilizar engajamentos políticos exequíveis, credíveis e, portanto, positivos. O caminho a percorrer é, então, o da responsabilidade para com os co-habitantes da biosfera assentada no princípio de que os mais fortes, ou ao menos aqueles que detêm condições de assim o serem, são os responsáveis pelo bem-estar e defesa dos mais fracos, ou dos que, por qualquer razão, estejam nessa posição. É nesse sentido que lemos as palavras do cronista quando diz: "como as imensas e bondosas mãos dos que protegem os mais fracos" (VILELA, 2005, p. 31) e isso vem, conforme palavras de Isabel Maria Fernandes Alves (2009, p. 43), a "acentuar o componente relacional que envolve todos os seres que habitam a biosfera".

A natureza, em Vilela, por conseguinte, para além do caráter utilitarista que lhe empresta o atual modelo de consumo predominante no Ocidente, é mesmo parte essencial da vida do homem, da sua história; que lhe fala e com ele coexiste. Vilela não disfarça, sua arte é de expressiva força estética e política. E que imagem de mundo constrói? Certamente é uma visão de mundo onde "as imensas e bondosas mãos protegem" e também da "proibição radical de qualquer tipo de rede". Redes que obstruem a "viagem das pobres corimbas", mas também que impedem uma relação entre homem e meio ambiente físico pautado pela responsabilidade e, com diria Leonardo Boff (2007), pelo cuidado. Imagem de um mundo de todos os homens, que têm, na Terra-Habitação, suas histórias que precisam ser contadas às futuras gerações. No entanto, em Vilela (2006), vemos que a vida do homem se confunde com a natureza para essa perpetuação e é somente por meio do cuidado do homem para com ela que essas histórias poderão ser contadas. 


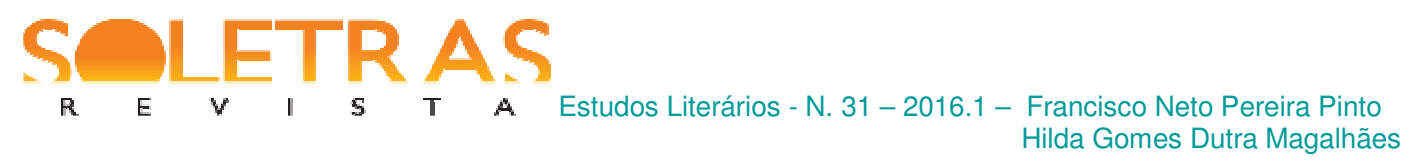

Vimos, pois, que esta última noção tempo, o tempo de cuidar, temporalidade em que o homem toma a natureza não segundo uma ótica instrumental, mas como um dos componentes da biosfera, da qual o próprio homem faz parte, é muito diferente da ressaltada inicialmente, tempo do Estado, temporalidade única, do homem moderno, que coloca este em uma relação de domínio sobre a natureza, instaurando, assim, colonialismo ambiental. A temporalidade performática é, pois, a temporalidade apropriada para essa nova relação, a de cuidado, na qual homem e natureza habitam essa que é nosso lar eterno, a Terra, em uma história que nunca acabará de ser contada.

\section{Referências:}

ANDERSON, B. Nação e consciência nacional. Trad. Lólio Lourenço de Oliveira. São Paulo: Ática, 1989.

ANTHONY, V. Toward an African Ecocriticism: Postcolonialism, Ecology and Life \& Times of Michael K. Research in African Literatures, v. 39, n. 1, p. 87-121, Spring 2008.

APPIAH, K. A. Is the post- in postmodernism the post- in postcolonial?. In: Critical Inquiry, v. 17, n. 2 , p. $336-57,1991$.

BAUDELAIRE, C. Sobre a modernidade: o pintor da vida moderna. Org. Teixeira Coelho. Rio de Janeiro: Paz e Terra, 1996.

BEALER, A. H. Reading Out Loud: Performing Ecocriticism as a Practice of the Wild. In: Interdiscip. Stud Lit. Environ, v. 19, n. 1, p. 5-23, Winter 2012. Disponível em: http://isle.oxfordjournals.org/content/19/1/5.full.pdf+html. Acessado em 27 de abril de 2014.

BERMAN, M. Tudo que é sólido se desmancha no ar: a aventura da modernidade. Trad. Carlos Felipe Moisés; Ana Maria L. Ioriatti. São Paulo: Companhia das Letras, 1986.

BHABHA, H. K. O local da cultura. Trad. Miriam Ávila; Eliana Lourenço de Lima Reis; Gláucia Renate Gonçalves. 3. reimp. Belo Horizonte: UFMG, 2005.

BOFF, L. Saber cuidar: ética do humano - compaixão pela terra. 13 ed. Petrópolis, RJ: Vozes, 2007.

BONNICI, T. O pós-colonialismo e a literatura: uma estratégia de leitura. Maringá:Eduem, 2000.

BRAGA, F.M.S. Aspectos da reprodução e alimentação de peixes comuns em um trecho do rio Tocantins entre Imperatriz e Estreito, Estados do Maranhão e Tocantins. In: Brasil. Rev. Bras. Biol, v. 50, n. 3, p. 547-58, 1990.

BRASIL. Instrução Normativa $n^{o} 36$, de 05 de outubro de 2005. Disponível em:<www.ibama.gov.br/rec_pesqueiros/legislacao.php?id_arq=147>.

Acessado em 


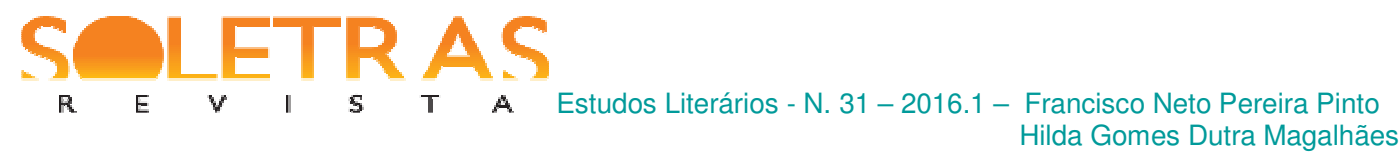

03/02/2010.

Instrução Normativa $n^{\circ} 39$, de 13 de outubro de 2005. Estabelecer normas para o período de defeso da piracema, temporada 2005/2006, na área da bacia hidrográfica do rio Uruguai, nos Estados de Santa Catarina e Rio Grande do Sul. Disponível em:<www.ibama.gov.br/cepsul/legislacao.php?id_arq=392> . Acessado em: 03/02/2010.

. Instrução Normativa $n^{\circ} 40$, de 18 de outubro de 2005. Estabelece normas para o período de proteção à reprodução natural dos peixes (piracema), na Bacia Hidrográfica do Rio Parnaíba. Disponível em: $<$ www.mp.ma.gov.br/site/centrosapoio/MeioAmbiente/.../IN40_2005.pdf $>$. Acessado em: $03 / 02 / 2010$.

Instrução Normativa $n^{\circ} 49,27$ de outubro de 2005.Estabelecer o período de $1^{\circ}$ - de novembro a 28 de fevereiro, de cada ano, como defeso da piracema na Bacia Hidrográfica do Rio Araguaia. Disponível em: <http://www.mp.go.gov.br/portalweb/hp/9/docs/in_ibama_4905.pdf>. Acessado em 03/02/2010.

CASTRO-GÓMES, S.; MENDIETA, E. INTRODUCCIÓN: La translocalización discursiva de "Latinoamérica" en tiempos de la globalización In: CASTRO-GÓMEZ, S. Teorías sin disciplina: Latinoamericanismo, poscolonialidad y globalización en debate / Santiago CastroGómez, Eduardo Mendieta, coord. México: University of San Francisco: M. A. Porrúa, 1998. Disponível em: <http://ensayo.rom.uga.edu/critica/teoria/castro/castroG.htm>. Acessado em 05/02/ 2009.

COUTO, H. H. Ecolinguística: estudo das relações entre língua e meio ambiente. Brasília, DF: 2007.

COSTA, S. Desprovincializando a Sociologia - a contribuição pós-colonial. In: Rev. Bras. Ciênc. Soc. v. 21, n. 60, p. 117-134, fev. 2006.

DIRLIK, A. A aura pós-colonial na era do capitalismo global. Novos Estudos Cebrap, n. 49, p. 7-32, 1997.

ELIAS, N. Sobre o tempo. Trad. Vera Ribeiro. Rio de Janeiro: Jorge Zahar, 1998.

FESTINO, C. G. Uma praja ainda imaginada: a representação de nação em três romances indianos de língua inglesa. São Paulo: Nankin: EDUSP, 2007.

FREITAS, M. Natureza, cultura, ambiente e desenvolvimento: um ensaio sobre a viabilidade de uma cultura (comum) da sustentabilidade. In: PARENTE, T. G. (Org.). Linguagens plurais: cultura e meio ambiente. Bauru: EDUSC, 2008. p.13-40.

MAGALHÃES, H. D. G. Linguagens plurais: cultura e meio ambiente. Bauru, SP: EDUSC, 2008. p. 13-40.

GARRARD, G. Ecocrítica. Trad. Vera Ribeiro. Brasília: Editora UNB, 2006.

GIDDENS, A. As consequências da modernidade. 2 ed. São Paulo: UNESP, 1991. 
HALL, S. Quando foi o pós-colonial?: pensando no limite. In: HALL, S. Da diáspora: identidades e mediações culturais. Organização de Liv Sovik; tradução de Adelaide La Guardia Resende et al. Belo Horizonte: Editora UFMG, 2003, p. 93-120.

HARVEY, D. Condição pós-moderna: uma pesquisa sobre as origens da mudança cultural. Tradução de Adail Ubirajara Sobral e Maria Stela Gonçalves. 15. ed. São Paulo: Loyla, 2006.

LOOMBA, A. Postcolonialism - Or postcolonial studies. Interventions, v. 1, n. 1, p. 39-42, 1998.

MACHADO, I. J. R. Reflexões sobre o pós-colonialismo. Teoria \& Pesquisa. São Carlos, v. 1. 44/45, p. 19-32, jan.-jun. de 2004.

MISHRA, V.; HODGE, B. What Was Postcolonialism?. In: New Literary History, v. 36, p. 375-402, 2005.

PESOA, N. A. Migração e Movimentos do Grumatã (Prochilodus lineatus, Valenciennes, 1836) (Characiformes, Prochilodontidae) no Rio dos Sinos, RS, Brasil, determinados por radiotelemetria 2010. Dissertação (Mestrado em Biologia) - Programa de Pós-Graduação em Biologia, Universidade do Vale dos Sinos. Disponível em: http://biblioteca.asav.org.br/vinculos/tede/NicollePesoaBiologia.pdf $>$. Acessado em: 15/02/2010.

REYNAUD, M. J. Abertura da Jornada de Reflexão sobre Ecocrítica: 25 de Novembro 2008. In: REYNAUD, M. J e ALMEIDA, J. D (Orgs.) Ecocrítica: jornada de reflexão. Écocritique: journée de réflexion, 2009, Porto: Universidade do Porto. Faculdade de Letras. Anais... Porto: Universidade do Porto. Faculdade de Letras, 2009, p. 3-5.

SANTOS, E.; SCHOR, P. Brasil, estudos pós-coloniais e contracorrentes análogas: entrevista com Ella Shohat e Robert Stam. In: Revista Estudos Feministas. Florianópolis, v. 21, n. 2, p. 701-26, maio-ago. 2013.

SOUSA SANTOS, B. Entre Próspero e Caliban: colonialismo, pós-colonialismo e interidentidade. Novos Estudos, 66, jul. 2003, p.23-5.

Do pós-moderno ao pós-colonial e para além de um e outro. In: Conferência de abertura ao VIII Congresso Luso-Afro Brasileiro de Ciências Sociais. Coimbra, Conferência de abertura ao VIII Congresso Luso-Afro-Brasileiro de Ciências Sociais, 2004.

SLOVIC, S. Ecocriticism: containing multitudes, practicing doutrine. In: ASLE News, Spring 1999. pp.5-6. Disponível em: $<$ www.asle.org/assets/docs/roundtable.pdf $>$. Acessado em: 05/02/2009.

SOHAT, E. Third World and Post-Colonial Issues. In: Social Text, n. 31/32, 1992, pp. 99-113. Disponível em: <http://www.jstor.org/sici?sici=01642472(1992)0\%3A 31\%2F32\%3C99\%/3ANOT\%22\%3E2.0.\%3B2E\&cookieSet=1>. Acessado em: 17/08/2008.

VIEIRA, E. R. P.. Postcolonialisms and the Latin Americas. Interventions, v. 1, n. 2, p. 273 - 
81, 1999.

VILELA, M. B. B. Crônicas e contos. Tocantinópolis, MS: Murilo Vilela, 2006.

WHITROW, G. J. O que é tempo? Uma visão clássica sobre a natureza do tempo. Trad. Maria Ignez Duque Estrada. Rio de Janeiro: Jorge Zahar, 2005.

YOUNG, R. J. C. Ideologies of the postcolonial. In: Interventions, v. 1, n.1, p. 4-8, 1998.

\title{
Times of piracemas: dialogue between Ecocriticism and Post-Colonialism
}

\begin{abstract}
We analyzed in this article chronic The spawning season of Tocantins, Murilo Brandão Vilela, using both as a theoretical framework, the Postcolonial Criticism and ecocriticism. Throughout the analysis, we demonstrated in the text a mismatch between the natural time of spawning and the time frame of environmental legislation regarding, which makes ineffective initiatives to protect and preserve the ideal conditions for the preservation of life in the Tocantins River.
\end{abstract}

Keywords: Spawning. Environment. Ecocriticism.

Recebido em: 21 de março de 2016.

Aprovado em: 12 de julho de 2016. 